\title{
Computed tomographic evidence of cerebral swelling in benign intracranial hypertension
}

\author{
P M Rothwell, R J Gibson, R J Sellar
}

\begin{abstract}
Computed tomography of 30 patients presenting acutely with benign intracranial hypertension was compared with that of 30 normal controls matched for age and sex. Qualitative and quantitative assessments showed smaller cranial CSF spaces in the cases of benign intracranial hypertension, suggesting that cerebral swelling is involved in the pathogenesis of benign intracranial hypertension.
\end{abstract}

$(\Im$ Neurol Neurosurg Psychiatry 1994;57:1407-1409)

The pathogenesis of benign intracranial hypertension is unknown. There have been conflicting reports of cerebral oedema, ${ }^{1}$ cerebral hyperaemia, ${ }^{2}$ and increased resistance to CSF drainage, ${ }^{3}$ but it remains unclear which element of the cerebral contents is increased in volume. The aim of this study was to examine the size of the cranial CSF spaces on CT of patients with benign intracranial hypertension compared with age and sex matched normal controls to determine whether raised intracranial pressure in benign intracranial hypertension is associated with an increase in volume of the cerebral tissues or the CSF.

Clinical

Neurosciences,

Edinburgh

P M Rothwell

R J Gibson

R J Sellar

Correspondence to:

Dr P M Rothwell, Dept of Clinical Neurosciences, Western General Hospital, Crewe Road, Edinburgh, EH4 2XU, UK.

Received 3 February 1994 and in revised form and in revised 19 May 1994.

Accepted 30 May 1994

\begin{abstract}
Methods
Thirty consecutive patients with newly diagnosed benign intracranial hypertension who presented to the Departments of Medical and Surgical Neurology in Edinburgh between 1985 and 1992 were studied. Inclusion criteria comprised papilloedema; a CSF pressure greater than $25 \mathrm{~cm}$ of water; normal CSF constituents; and no evidence of intracranial
\end{abstract}

mass lesion or hydrocephalus. Computed tomography was performed on a General Electric 8800 scanner at the initial presentation with suspected benign intracranial hypertension. The 30 control CT scans were derived from scans of a cohort of 62 patients with peripheral sensory symptoms, in whom detailed inpatient investigation showed no pathology of the CNS. Cases were paired with controls according to sex and nearest date of birth. No other criteria were used and matching was blind to the CT appearance.

On two occasions, three months apart, the 60 scans were shown independently to two neuroradiologists (RJG and RJS) who were blind to the clinical diagnosis. They were asked to grade the lateral ventricles as small, normal, or large, the third ventricle as normal, slit, or absent, and the cerebral sulci as normal or effaced. Each scan from a patient with benign intracranial hypertension was then presented with an age and sex matched control scan and the neuroradiologist was asked to indicate which scan suggested the lower cranial CSF volume. The size of the third and lateral ventricles, the sulci, and the basal cisterns were each taken into account in this qualitative assessment.

Three previously validated quantitative indices of ventricular size-the Huckman Index, ${ }^{4}$ the inverse cella media index, ${ }^{5}$ and the third ventricular diameter ${ }^{6}$-were also measured on the 60 scans by a single observer (PMR) who was blind to the clinical details.

\section{Results}

Only abnormal CT scan findings on which both radiologists agreed are reported. Small lateral ventricles, a slit or absent third ventricle, and effaced cerebral sulci were each significantly more frequent in cases of benign intracranial hypertension than in controls (table 1). The radiologists agreed on which scan showed the smaller cranial CSF spaces in 28 of the 30 case and control pairs (93\%), choosing the benign intracranial hypertension scan in $24(86 \%)$. The between observer and within observer agreements of the radiologists for each of the CT assessments were high (table 2). The mean values of each of the three quantitative indices of ventricular size were significantly lower in cases of benign intracranial hypertension than in controls
Table 1 Qualitative assessments on CT of 30 cases of benign intracranial hypertension

\begin{tabular}{lllll}
\hline & $\begin{array}{l}\text { Small lateral } \\
\text { ventricles }\end{array}$ & $\begin{array}{l}\text { Slit/absent } \\
\text { 3rd ventricle }\end{array}$ & $\begin{array}{l}\text { Effaced } \\
\text { Sulci }\end{array}$ & $\begin{array}{l}\text { Smaller cranial } \\
\text { CSF spaces }\end{array}$ \\
\hline CT: & & & & \\
$\quad$ Cases $(\mathrm{n}=30)$ & 9 & 15 & 13 & 24 \\
$\quad$ Controls $(\mathrm{n}=30)$ & 1 & 2 & 1 & 4 \\
$\begin{array}{l}\text { Odds ratio } \\
(95 \% \mathrm{CI})\end{array}$ & $12 \cdot 4$ & 14 & 22 & 6 \\
\hline
\end{tabular}


Table 2 The reproducibility (kappa statistic (SD)) of the qualitative assessments of the two neuroradiologists on 60 CT scans

\begin{tabular}{llll}
\hline & $\begin{array}{l}\text { Between } \\
\text { observer } \\
\text { agreement }\end{array}$ & \multicolumn{2}{l}{ Within observer agreement } \\
\cline { 3 - 4 } Assessment & $A$ & $B$ \\
\hline Size of third ventricle & $0.7(0.09)$ & $0.85(0.06)$ & $0.74(0.07)$ \\
Size of lateral ventricles & $0.56(0.11)$ & $0.60(0.11)$ & $0.54(0.12)$ \\
Effacement of sulci & $0.68(0.1)$ & $0.91(0.06)$ & $0.78(0.12)$ \\
Smaller cranial CSF spaces & $0.76(0.08)$ & $0.82(0.07)$ & $0.80(0.07)$ \\
\hline
\end{tabular}

Table 3 Mean (SD) values of three quantitative measures of ventricular size in $60 \mathrm{CT}$ brain scans

\begin{tabular}{llll}
\hline & $\begin{array}{l}\text { Third ventricle } \\
\text { diameter }(\mathrm{mm})\end{array}$ & $\begin{array}{l}\text { Huckman } \\
\text { index }\end{array}$ & $\begin{array}{l}\text { Inverse cella } \\
\text { media index }\end{array}$ \\
\hline CT: & & & \\
BIH cases $(\mathrm{n}=30)$ & $0 \cdot 70(0 \cdot 46)$ & $49(21)$ & $0.074(0 \cdot 02)$ \\
Controls $(\mathrm{n}=30)$ & $1 \cdot 44(0 \cdot 68)$ & $73(27)$ & $0 \cdot 124(0 \cdot 07)$ \\
\hline
\end{tabular}

$\mathrm{BIH}=$ benign intracranial hypertension. (table 3), indicating a smaller ventricular size in patients with benign intracranial hypertension.

\section{Discussion}

Small lateral ventricles, a slit or absent third ventricle, and effaced cerebral sulci were often seen on CT in cases of benign intracranial hypertension, but rarely in controls. When age and sex matched case and control scans were compared directly, the benign intracranial hypertension scans showed consistently smaller cranial CSF spaces than controls. The high between and within observer agreements for these qualitative assessments support their validity. Indeed, such highly reproducible qualitative measures are likely to be more valid than arbitrary and technically difficult semiquantitative measures. ${ }^{4}$

Five previous studies have looked at cerebral ventricular size by CT of patients with benign intracranial hypertension..$^{7-11}$ Only one found small ventricles, but CT of patients with multiple sclerosis and cerebrovascular disease, which may be associated with cerebral atrophy and ventricular enlargement, were used as controls. ${ }^{11}$ Of the remaining studies, three had no controls ${ }^{7-9}$ and all were limited by the small number of cases. The sizes of the other cranial CSF spaces, such as the basal cisterns and cerebral sulci have not been studied.

Small or slit lateral ventricles, a slit or absent third ventricle, and effaced basal cisterns and sulci are seen on CT after acute head injury and correlate with the severity of raised intracranial pressure and the degree of cerebral swelling at postmortem. ${ }^{1213}$ The identical CT findings in this study raise the possibility that cerebral swelling is important in the pathogenesis of raised intracranial pressure in benign intracranial hypertension. This is supported by the finding that ventricular size on CT, ${ }^{14}$ and cranial CSF volume, measured with MRI, ${ }^{15}$ increase with resolution of benign intracranial hypertension.

It is possible that small cranial CSF spaces in patients with benign intracranial hyperten- sion are constitutional and might predispose the patient to develop raised intracranial pressure. The Monro-Kellie doctrine states that the cranial contents are incompressible and the total intracranial volume must remain constant. Raised intracranial pressure due to cerebral swelling, caused by oedema or hyperaemia, can only be compensated for by a reduction in cranial CSF volume. In patients with constitutionally small cranial CSF spaces, this compensatory capacity would be limited, thereby increasing the risk of developing raised intracranial pressure in response to minor degrees of cerebral swelling.

The reduction in the size of the cranial CSF spaces relative to the cerebral volume in cases of benign intracranial hypertension, compared with controls, does not support the popular hypothesis that raised intracranial pressure in patients with benign intracranial hypertension is caused by an increased resistance to CSF reabsorption. ${ }^{3}$ There is disagreement as to whether increased resistance to reabsorption of CSF would necessarily lead to hydrocephalus, but even if it is accepted that hydrocephalus would not ensue, it is difficult to explain the smaller than expected cranial CSF spaces. Increased intracranial pressure leads to reflex cerebral vasodilation, which maintains cerebral blood flow. ${ }^{16}$ Raised intracranial pressure due to resistance to CSF drainage could in theory cause cerebral swelling due to this reflex increase in cerebral blood volume. Animal experiments, however, suggest that the increase in cerebral blood volume expected at the levels of intracranial pressure found in benign intracranial hypertension is small, equivalent to less than $1 \%$ of cranial volume. ${ }^{17}$ There is evidence of increased cerebral blood volume in patients with benign intracranial hypertension, but the increase is much greater than would be expected from autoregulation alone, ${ }^{1618}$ and there is no fall in cerebral blood flow after restoration of intracranial pressure to normal by lumbar puncture. ${ }^{17}$ Moreover, the largest and most detailed study of CSF haemodynamics in benign intracranial hypertension found that in most cases, resistance to CSF reabsorption was normal or only moderately increased, and concluded that such changes were probably secondary to compression of the venous sinuses and lateral lacunae due to cerebral swelling. ${ }^{19}$ This is consistent with the finding of increased resistance to CSF reabsorption in association with cerebral tumours and other conditions associated with raised intracranial pressure. ${ }^{2021}$ The findings of our study support the hypothesis that cerebral swelling is the primary pathophysiological event in benign intracranial hypertension. Further research is required to determine whether this is due to oedema or hyperaemia.

1 Sahs AL, Joynt RJ. Brain swelling of unknown cause. Neurology 1956;6:791-803.

2 Mathew NT, Meyer JS, Otto EO. Increased cerebral blood volume in benign intracranial hypertension. Neurology 1975;25:646-9. 
3 Johnstone I. Reduced CSF absorption syndrome Reappraisal of benign intracranial hypertension and Reappraisal of benign intracranial hype

4 Huckman MS, Fox J, Topel J. The validity of criteria for the evaluation of cerebral atrophy by computed tomography. Radiology 1975;116:85-92.

5 Haug G. Age and sex dependence of the size of normal ventricles on computed tomography. Neuroradiology 1977;14:201-4.

6 Colquhoun IR, Burrows EH. The prognostic significance of the third ventricle and basal cisterns in severe closed head injury. Clin Radiol 1989;40:13-6.

7 Delaney P, Schellinger D. Computerised tomography and benign intracranial hypertension. $7 A M A$ 1976;236: 951-2.

8 Weisberg LA. Computed tomography in benign intracranial hypertension. Neurology 1985;35:1075-8.

9 Vassilouthis J, Uttley D. Benign intracranial hypertension: Clinical features and diagnosis using computed tomoClinical features and diagnosis using computed to

10 Huckman MS, Fox JS, Ramsey RG, Penn RD. Computed tomography in the diagnosis of pseudotumour cerebri.

11 Reid AC, Matheson MS, Teasdale G. Volume of the ventricles in benign intracranial hypertension. Lancet 1980;ii:7-8.

12 O'Holliday P, Kelly DL, Ball M. Normal computed tomograms in acute head injury: correlation of intracranial pressure, ventricular size, and outcome. Neurosurgery 1982;10:25-8.
13 Teasdale E, Cardoso E, Galbraith S, Teasdale G. CT scan in severe diffuse head injury: Physiological and scan in severe diffuse head injury: Physiological and
clinical correlations. $₹$ Neurol Neurosurg Psychiatry 1984; 47:600-3.

14 Reid AC, Teasdale GM, Matheson MS, Teasdale EM. Serial ventricular volume measurements: further insights into the aetiology and pathogenesis of benign intracranial hypertension. If Neurol Neurosurg Psychiatry $1981 ; 44: 636-40$

15 Grant R, Condon B, Teasdale GM. BIH: Brain swelling and cranial CSF volume. Intracranial pressure and brain injury, 7th International Symposium. Ann Arbor, USA, June 1988 [abstract] Proc ICP VII; 341-3.

16 Langfitt TW, Kassell NF, Weinstein JD. Cerebral blood flow with intracraniat hypertension. Neurology (Minneap) 1965;15:761-3.

17 Raichle ME, Grub RL, Phelps ME, Gado MH, Caronna JJ. Cerebral haemodynamics and metabolism in pseudoJu. Cerebral haemodynamics and metabolism

18 Mathew NT, Meyer JS, Ott EO. Increased cerebral blood volume in benign intracranial hypertension. Neurology 1975;25:646-9.

19 Malm J, Kristensen B, Markgren P, Ekstedt J. CSF haemodynamics in idiopathic intracranial hypertension: A long term study. Neurology 1992;42:851-8.

20 Van Crevel H. Papilloedema, CSF pressure, and CSF flow in cerebral tumours. I Neurol Neurosurg Psychiatry 1979;42:493-500.

21 Hayashi M, Handa Y, Kobayashi $\mathrm{H}$, et al. Plateau-wave phenomenon. Brain 1991;114:2681-91. 